\title{
OBSERVATION OF 23 SUPERNOVAE THAT EXPLODED <300 pc FROM EARTH DURING THE PAST 300 kyr
}

\author{
R. B. FIRESTONE \\ Lawrence Berkeley National Laboratory, Berkeley, CA 94720, USA; rbfirestone@1bl.gov \\ Received 2014 March 10; accepted 2014 May 7; published 2014 June 11
}

\begin{abstract}
Four supernovae (SNe), exploding $\leqslant 300 \mathrm{pc}$ from Earth, were recorded 44, 37, 32, and $22 \mathrm{kyr}$ ago in the radiocarbon $\left({ }^{14} \mathrm{C}\right)$ record during the past 50 kyr. Each SN left a nearly identical signature in the record, beginning with an initial sudden increase in atmospheric radiocarbon, when the SN exploded, followed by a hiatus of $1500 \mathrm{yr}$, and concluding with a sustained $2000 \mathrm{yr}$ increase in global radiocarbon due to $\gamma$-rays produced by diffusive shock in the SN remnant (SNR). For the past $18 \mathrm{kyr}$ excess radiocarbon has decayed with the ${ }^{14} \mathrm{C}$ half-life. SN22kyrBP, is identified as the Vela SN that exploded $250 \pm 30 \mathrm{pc}$ from Earth. These SN are confirmed in the ${ }^{10} \mathrm{Be},{ }^{26} \mathrm{Al}$, ${ }^{36} \mathrm{Cl}$, and $\mathrm{NO}_{3}^{-}$geologic records. The rate of near-Earth $\mathrm{SNe}$ is consistent with the observed rate of historical $\mathrm{SNe}$ giving a galactic rate of $14 \pm 3 \mathrm{kyr}^{-1}$ assuming the Chandra Galactic Catalog SNR distribution. The Earth has been used as a calorimeter to determine that $\approx 2 \times 10^{49}$ erg were released as $\gamma$-rays at the time of each SN explosion and $\approx 10^{50}$ erg in $\gamma$-rays following each $\mathrm{SN}$. The background rate of ${ }^{14} \mathrm{C}$ production by cosmic rays has been determined as 1.61 atoms $\mathrm{cm}^{-2} \mathrm{~s}^{-1}$. Approximately $1 / 3$ of the cosmic ray energy produced by diffusive shock in the SNR was observed to be emitted as high-energy $\gamma$-rays. Analysis of the ${ }^{10} \mathrm{Be} /{ }^{9} \mathrm{Be}$ ratio in marine sediment identified 19 additional near-Earth SNe that exploded 50-300 kyr ago. Comparison of the radiocarbon record with global temperature variations indicated that each $\mathrm{SN}$ explosion is correlated with a concurrent global warming of $\approx 3^{\circ} \mathrm{C}-4^{\circ} \mathrm{C}$.
\end{abstract}

Key words: cosmic rays - Earth - ISM: supernova remnants - supernovae: general

Online-only material: color figures

\section{INTRODUCTION}

Enrico Fermi (1949) proposed the production of cosmic rays by diffusive shock acceleration at the outer front of expanding supernova remnants (SNRs). This prediction has recently been confirmed in observations by the Fermi Large Area Telescope collaboration (Ackerman et al. 2013). Detailed calculations have suggested that most of the SN explosion energy is converted into cosmic rays over a period of many centuries (Hillas 2005; Ellison et al. 2004; Berezhko et al. 2002). It was calculated (Berezhko et al. 2002) for the SN1006 supernova that $\approx 3 \times$ $10^{50} \mathrm{erg}, 60 \%$ of the explosion energy, was released as cosmic rays. Hadronic cosmic rays, mostly protons, diffuse slowly out of the SNR radiating from $1 \%-50 \%$ of their energy as secondary, high energy $\gamma$-rays (Povinek \& Tokar 1979) by bremsstrahlung, pion decay, and inverse Compton processes. At the time of the SN explosion $\gamma$-rays with $E_{\gamma}<20 \mathrm{GeV}$ may be produced as the high energy particles in the relativistic shock wave breaks through the SN envelope (Colgate \& White 1968). It has been predicted (Povinek \& Tokar 1979) that $\gamma$-rays emitted from a SN exploding $1 \mathrm{kpc}$ from Earth would increase atmospheric radiocarbon by $1 \%-2 \%$ at the time of the explosion. Much later, cosmic $\gamma$-rays with energies up to $E_{\gamma}>100 \mathrm{TeV}$ are produced over a period of $<10^{4} \mathrm{yr}$, as particles accelerated in the SNR interact with the explosion and swept-up mass and the ISP gas (Dermer \& Powale 2013). Explosions of near-Earth SNe will subsequently deposit substantial amounts of $\gamma$-ray energy into Earth's atmosphere producing ${ }^{14} \mathrm{C}$ and other cosmogenic isotopes that are subsequently recorded in Earth's geological record. This suggests that the Earth is an optimum calorimeter for quantitatively detecting the cosmic gamma ray emission following nearby $\mathrm{SN}$ explosions.

During the past millennium approximately six $\mathrm{SNe}$ are known to have exploded within $\approx 3 \mathrm{kpc}$ of Earth. These $\mathrm{SNe}$ were reported in historical records from Asia and Europe (Green 2004) and are listed in Table 1. Terrestrial evidence of these $\mathrm{SNe}$ were also observed in the thermoluminescence analysis of Tyrrhenian Sea sediment profiles (Castagnoli et al. 1982). Castagnoli et al. estimated that the local cosmic ray energy influx from SN1054 $(2.0 \mathrm{kpc})$ was $10^{6} \mathrm{erg} \mathrm{cm}^{-2}$ corresponding to a total energy release of $\approx 4 \times 10^{50} \mathrm{erg}$. Sudden increases in nitrate abundance in Antarctic ice cores (Rood et al. 2003; Dreschhoff \& Laird 2006), from hard SN x-rays and $\gamma$-rays, have also been observed at the times of five of the six historic $\mathrm{SNe}$. It was reported that an $0.61 \pm 0.16 \%$ increase in tree ring radiocarbon (Damon et al. 1995) followed the explosion of SN1006, that occurred $1.56 \mathrm{kpc}$ from Earth (Jiang \& Zhao 2007), which is consistent with the prediction of Povinec and Tokar.

Nearby Type II SNe are expected to occur in regions of active star formation such as the twelve OB star associations that lie within 650 pc of Earth (de Zeeuw et al. 1999). For example, Scorpius-Centaurus OB, 116-144 pc from Earth (Hernandez et al. 2005), contains 6 stars with more than 10 solar masses (Preibisch et al. 2002). It is estimated (Benítez et al. 2002) that $\approx 20 \mathrm{SNe},<130 \mathrm{pc}$ from Earth, have exploded during the past 11 million years. Assuming SNe are randomly distributed throughout the nearby regions of the galactic disk, based on the historical SN rate, we would expect $\approx 3 \mathrm{SNe}$ to have exploded within $300 \mathrm{pc}$ of Earth during the past $50 \mathrm{kyr}$.

In 1949 Libby et al. (1949) developed the radiocarbon dating method for dating fossil carbon. Radiocarbon is produced primarily by the ${ }^{14} \mathrm{~N}(\mathrm{n}, \mathrm{p}){ }^{14} \mathrm{C}$ nuclear reaction from secondary neutrons generated by cosmic ray interactions with the atmosphere. Radiocarbon reaches equilibrium between atmospheric, terrestrial and oceanic carbon reservoirs via the global carbon cycle (Schimel 1995), as described in Figure 1, and is retained in annual tree ring and sediment records. 


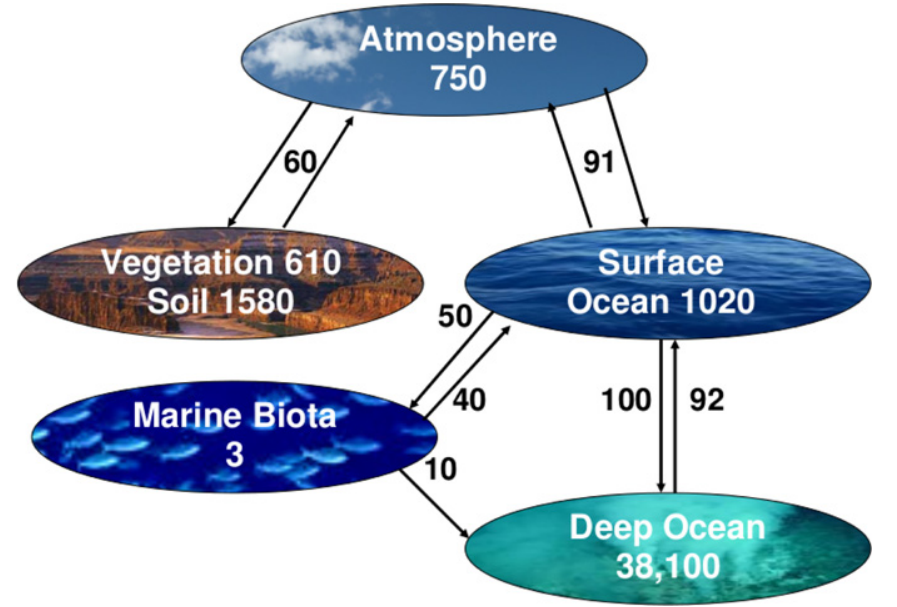

Figure 1. Global carbon cycle (Schimel 1995). The atmospheric, terrestrial, and ocean carbon pools are in equilibrium. The carbon reservoirs and annual exchange rates are given in billions of metric tons. Volcanic activity (not shown) contributes 2 metric tons to the atmosphere. Radiocarbon $\left({ }^{14} \mathrm{C}\right)$ is in equilibrium with global carbon and the radiocarbon abundance in the pools can be determined by multiplying by $1.2 \times 10^{-12}$ (Roberts \& Southon 2007).

(A color version of this figure is available in the online journal.)

Table 1

Historical Supernovae

\begin{tabular}{lccl}
\hline \hline Date & Location & $\begin{array}{c}\text { Common } \\
\text { Name }\end{array}$ & $\begin{array}{l}\text { Dist. } \\
(\mathrm{kpc})\end{array}$ \\
\hline 1006 Apr 30 & Lupus & SN 1006 & $1.56^{\mathrm{a}}$ \\
1054 Jul 4 & Taurus & Crab & 2.0 \\
1181 Aug 6 & Cassiopeia & SN 1181 & 3.2 \\
1572 Nov 6 & Cassiopeia & Tycho & 2.3 \\
1604 Oct 9 & Ophiuchus & Kepler & 2.9 \\
$1671^{\text {b }}$ & Cassiopeia & Cas A & 3.4 \\
\hline
\end{tabular}

Notes. Data compiled by David Green (Green 2004).

${ }^{a}$ From Jiang \& Zhao (2007).

${ }^{b}$ Not recorded historically. The age is from the expansion rate of the SNR.

The atmospheric ${ }^{14} \mathrm{C}$ reservoir is small, containing $\approx 2 \%$ of global radiocarbon, so sudden changes in the cosmic ray rate can change atmospheric radiocarbon abundance rapidly. However, $\approx 12 \%$ of atmospheric radiocarbon exchanges annually with the much larger ocean ${ }^{14} \mathrm{C}$ reservoir, so atmospheric radiocarbon quickly returns to global levels. The global ${ }^{14} \mathrm{C}$ abundance can only increase in response to truly massive cosmic ray events, in which case the high levels of radiocarbon will persist in all reservoirs until it decays away with a $5730 \mathrm{yr}$ half-life.

Libby assumed that the radiocarbon abundance, ${ }^{14} \mathrm{C} / \mathrm{C}$, in living organisms was always constant so that the age of a fossil could be determined simply by measuring the amount of ${ }^{14} \mathrm{C}$ remaining following its death. Soon it became apparent, when comparing with alternate dating methods, that ${ }^{14} \mathrm{C} / \mathrm{C}$ was much larger in the past. This required the direct determination of earlier radiocarbon abundance calibration data in order to accurately date fossils. The higher ${ }^{14} \mathrm{C} / \mathrm{C}$ ratio indicates that the cosmic ray rate striking the atmosphere was much larger at earlier times. This can occur if Earth's magnetic field was much lower in the past (Elsasser et al. 1956), there was a massive solar flare, a $\gamma$-ray burst or galactic core explosion occurred, or a near-Earth SN exploded. For example, a significant increase in global radiocarbon might be expected to occur following the

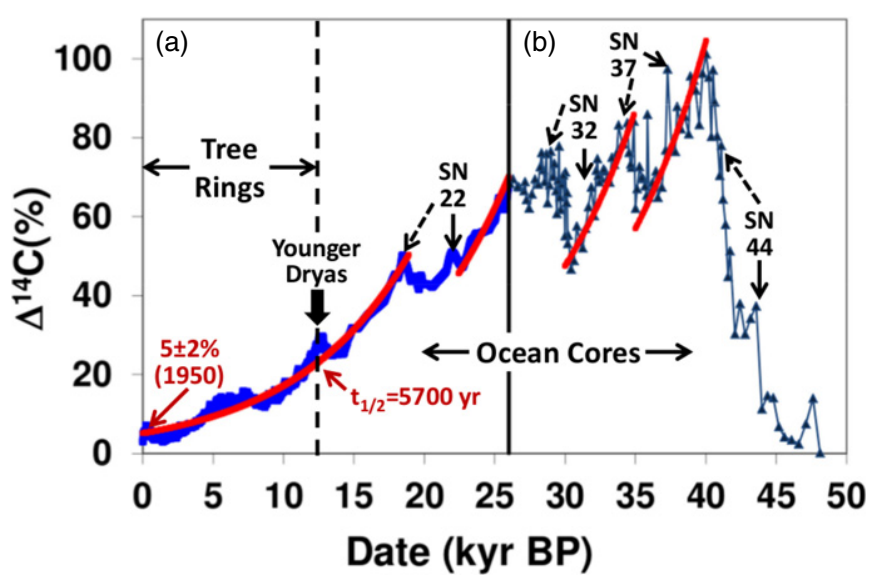

Figure 2. Radiocarbon record for the past $50 \mathrm{kyr} . \Delta^{14} \mathrm{C}(\%)$ data are (a) based on tree ring (12.4-0 cal kyr BP) and corals and foraminifera in ocean cores (26.0-12.4 cal kyr BP), from INTCAL04 (Reimer et al. 2003) and (b) based on the Cariaco Basin ocean core from Hugh et al. (Hughen et al. 2004) (26-50 cal kyr BP). The data from Hugh et al. were renormalized to match the INTCAL04 $\Delta^{14} \mathrm{C}(\%)$ values at 26 cal kyr BP. Relative uncertainties in the data are seen in the scatter of adjacent data points. Four sudden increases in $\Delta^{14} \mathrm{C}(\%)$ are observed 44, 37, 32, and 22 kyr ago, indicated by solid arrows, each followed by broader increases continuing for several kyr, indicated by dashed arrows. These radiocarbon increases are ascribed to $\mathrm{SN}$, and $\mathrm{SN} 22 \mathrm{kyrBP}$ has been associated with the Vela SN. The excess ${ }^{14} \mathrm{C}$ produced by each $\mathrm{SN}$ decreases with the expected $5730 \mathrm{yr}$ half-life as indicated by the red curves. Decay of ${ }^{14} \mathrm{C}$ during the past $18 \mathrm{kyr}$ establishes an absolute normalization for $\Delta^{14} \mathrm{C}(\%)_{0}$ in 1950 of $5 \% \pm 2 \%$. An additional increase in $\Delta^{14} \mathrm{C}(\%)$ that occurred $13 \mathrm{kyr}$ ago does not appear to be related to a $\mathrm{SN}$ explosion.

(A color version of this figure is available in the online journal.)

explosion of the Vela SN $250 \pm 30$ pc from Earth (Cha et al. 1999). In this paper I will explore the radiocarbon geologic record for evidence of Vela SN and other recent, near Earth cosmic ray producing events.

\section{RESULTS}

The IntCal working group was established to set the criteria for acceptance of data into the radiocarbon calibration data set (Reimer et al. 2002) that is used to correct radiocarbon dates for the actual amount of ${ }^{14} \mathrm{C}$ in the atmosphere in the past. Figure 2 shows the excess radiocarbon, $\Delta^{14} \mathrm{C}(\%)$ for the past $50 \mathrm{kyr}$. The original relative normalization scale, $\Delta^{14} \mathrm{C}(\%)=0.0$ in 1950 , was set arbitrarily at the beginning of the nuclear age and has been adjusted in this work to an absolute scale based on the analysis discussed below. Data for 0-26 kyr BP in Figure 2(a) are from the INTCAL04 radiocarbon calibration (Reimer et al. 2003), based on tree ring (0-12.4 kyr BP) and marine sediment (12.4-26.0 kyr BP) records. Data for 26-50 kyr BP (Hughen et al. 2004) in Figure 2(b) are based on measurements of a Cariaco Basin ocean core off of the coast of Venezuela. The $\Delta^{14} \mathrm{C}(\%)$ values from Hughen et al. were systematically lower than the INTCAL04 data and have been increased by $22.5 \%$ to coincide with INTCAL04 results at $26 \mathrm{kyr}$ BP. A more recent radiocarbon calibration, INTCAL09 (Reimer et al. 2009), published for 0-50 kyr BP, has been rejected in this analysis. These data are comparable to INTCAL04 for 0-26 kyr BP, but significant differences exist for the earlier data. The INTCAL09 evaluation combines numerous discrepant measurements by using a Markov Chain Monte Carlo (MCMC) approach to fit the data leading to rapid, nonphysical fluctuations in $\Delta^{14} \mathrm{C}(\%)$ that appear to arise from the fitting procedure. 


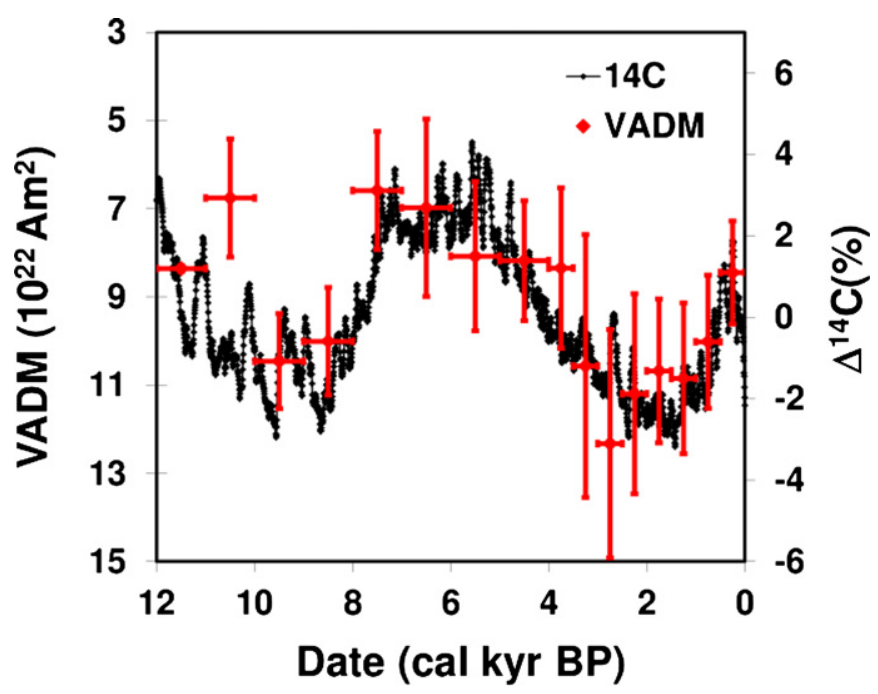

Figure 3. Correlation between oscillations in the ${ }^{14} \mathrm{C}$ decay rate and variations in Earth's magnetic field. The differences between $\Delta^{14} \mathrm{C}$ data and the fitted exponential decay curve for the past $12 \mathrm{kyr}$ are compared with variations in Earth's Virtual Axial Dipole Moment (VADM; McElhinny \& Senanayake 1982). Excess radiocarbon varies inversely with the changes in VADM, which is consistent with a weaker magnetic field shielding the Earth less effectively from cosmic rays.

(A color version of this figure is available in the online journal.)

\subsection{6-0 kyr Radiocarbon Data}

The quantity of excess radiocarbon, $\Delta^{14} \mathrm{C}(\%)$, appears to decrease exponentially during the period from 18-0 kyr BP, albeit with minor oscillations. This implies that a large pool of excess global radiocarbon has been decaying for a long time. These data can be fit to the exponential decay formula

$$
\left[\Delta^{14} C_{t}-\Delta^{14} C_{0}\right]=\left[\Delta^{14} C_{t=0}-\Delta^{14} C_{0}\right] e^{-\lambda t}
$$

where the half-life $t_{1 / 2}=\ln (2) / \lambda$ and $\Delta^{14} C(\%)_{0}$ is the amount of excess radiocarbon in 1950 . A least-squares exponential fit to the $18-0 \mathrm{kyr} \Delta \Delta^{14} \mathrm{C}(\%)$ data gives $t_{1 / 2}=5700 \pm 700 \mathrm{yr}$, which is consistent with the recommended ${ }^{14} \mathrm{C}$ half-life $\left(t_{1 / 2}=5730 \pm\right.$ $40 \mathrm{yr}$ ) (Godwin 1962). The fit also gives $\Delta^{14} C_{0}=5 \% \pm 2 \%$, which would be the first determination of an absolute scale for global radiocarbon abundance in 1950.

\subsubsection{Earth's Magnetic Field Effects}

Small oscillations about the $\Delta^{14} \mathrm{C}(\%)$ decay curve for the past $18 \mathrm{kyr}$ are seen in Figure 2(a) and can be explained by fluctuations in Earth's magnetic field. To test this hypothesis, the variations between the fitted decay curve and the measured $\Delta^{14} \mathrm{C}(\%)$ values are compared with the measured fluctuations in the magnitude of Earth's Virtual Axial Dipole Moment (VADM; McElhinny \& Senanayake 1982) in Figure 3. The VADM was independently determined from the remnant magnetism in well dated sediments from the past $12 \mathrm{kyr}$. The fluctuations in $\Delta^{14} \mathrm{C}(\%)$ are inversely proportional and well correlated with the strength of Earth's magnetic field. This is consistent with the strength of Earth's magnetic field modulating the intensity of cosmic rays that can strike the Earth. The variations in the cosmic ray rate striking the Earth due to oscillations in the magnetic field changes $\Delta^{14} \mathrm{C}(\%)$ by only $\pm 2 \%$, which is small compared to $\Delta^{14} \mathrm{C}(\%)=70 \%, 26 \mathrm{kyr}$ ago.

\subsubsection{Detection of the Vela $S N$}

Figure 2(a) shows that a sudden increase in $\Delta^{14} \mathrm{C}(\%)$ occurred $22 \mathrm{kyr}$ ago and was followed by a second, broader increase $20-18$ kyr ago. This is consistent with the explosion of a nearEarth SN $22 \mathrm{kyr}$ ago, referred to here as SN22kyrBP, that produced a rapid initial increase in atmospheric radiocarbon from $\gamma$-rays emitted at the time of the explosion followed by a prolonged increase in global radiocarbon later from the $\gamma$-rays produced by secondary reactions of accelerated hadronic cosmic rays with the accumulated mass in the SNR. The second increase in global ${ }^{14} \mathrm{C}$ is followed by the decay of accumulated ${ }^{14} \mathrm{C}$ with a 5730 yr half-life as described earlier.

The date of SN22kyrBP is consistent with the age of the Vela SN as determined from both its pulsar distance to the SNR $(18 \pm 9 \mathrm{kyr})$ (Aschenbach et al. 1995) and SNR size (31 $\pm 6 \mathrm{kyr})$ (Chanmugam et al. 1995), but it is inconsistent with the $11 \mathrm{kyr}$ age derived from the pulsar spin-down rate (Strom et al. 1995). The spin-down value may be unreliable due to sudden variations in the magnetic field of a young pulsar (Chanmugam et al. 1995) and is ruled out by the lack of evidence for an $\mathrm{SN}$ at that time in the radiocarbon record. Figure 2 also shows that $\Delta^{14} \mathrm{C}(\%)$ was $27 \%$ higher $26 \mathrm{kyr}$ ago than immediately before the SN22kyrBP explosion suggesting that additional, earlier near-Earth $\mathrm{SNe}$ have contributed to the excess radiocarbon abundance.

\subsection{0-26 kyr Radiocarbon Data}

Figure 2(b) shows that radiocarbon abundance was similar to modern times $>44 \mathrm{kyr}$ ago. Global radiocarbon suddenly doubled 44-40 kyr BP, presumably from a SN referred to here as SN44kyrBP. This increase was previously ascribed to geomagnetically modulated changes in the cosmic ray flux (Hughen et al. 2004) associated with the Laschamp and Mono Lake geomagnetic excursions (Beck et al. 2001; Masarik \& Beer 1999) and/or interruptions in ocean circulation. Those explanations are inadequate because in order for the large pool of global radiocarbon to increase so rapidly it would require a 7 -fold increase in the rate of ${ }^{14} \mathrm{C}$ production as shown in Figure 4. That rate greatly exceeds the maximum 2-3fold increase in the rate of radiocarbon production calculated (Masarik \& Beer 1999) assuming Earth's magnetic field were to completely disappear during that entire time. A 3-fold increase in the rate of ${ }^{14} \mathrm{C}$ production would require $16 \mathrm{kyr}$ for $\Delta^{14} \mathrm{C}(\%)$ to double. There is no evidence that Earth's magnetic field has ever disappeared for such a long time. A shutdown of the ocean circulation could temporarily increase the accumulation of radiocarbon in the atmosphere, but when carbon cycling resumed this would rapidly restore radiocarbon to its normal equilibrium as $12 \%$ of atmospheric carbon is exchanged annually with the much larger ocean (Schimel 1995) reservoir. After global radiocarbon doubled 44-40 kyr ago it remained continuously high, with modest fluctuations, for many thousands of years indicating that the increase did not simply occur in the small atmospheric radiocarbon reservoir, but in the entire global radiocarbon pool. Similar sudden increases in $\Delta^{14} \mathrm{C}(\%)$ are also seen 37-33 kyr (SN37kyrBP) and 32-28 kyr (SN32kyrBP) ago in Figure 2(b). Each is followed by the decay of excess radiocarbon with the ${ }^{14} \mathrm{C}$ half-life. A total of four near-Earth $\mathrm{SNe}$ are proposed to have exploded during the past $50 \mathrm{kyr}$, which is comparable to the rate expected from historical observations. 


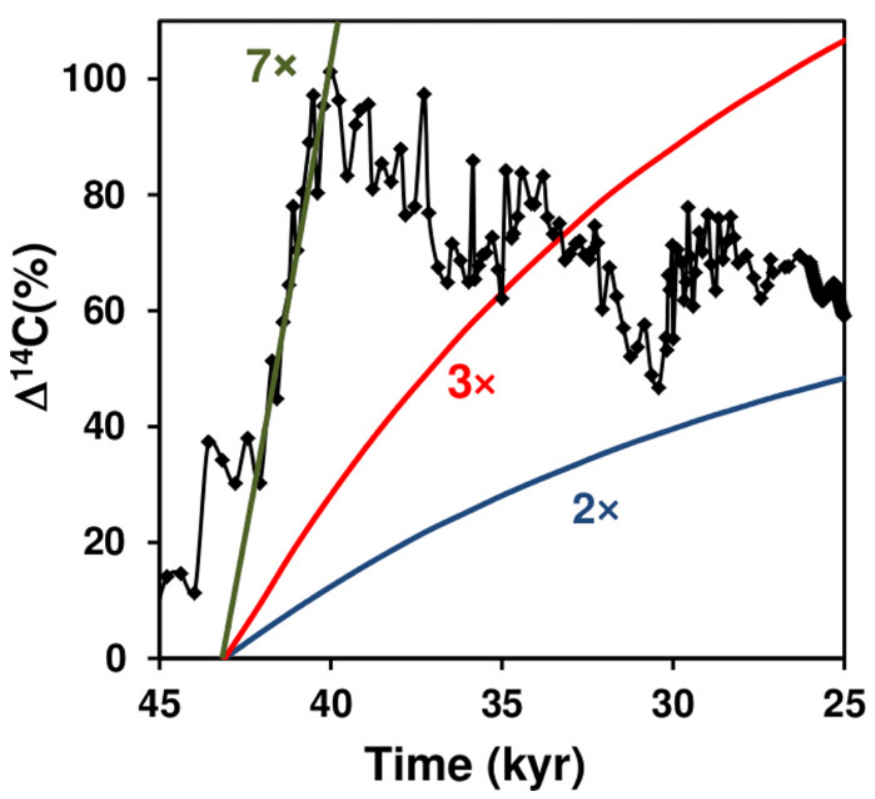

Figure 4. Increase in global radiocarbon for various cosmic ray rate assumptions. The calculated increase in $\Delta^{14} \mathrm{C}(\%)$ assuming sustained 2-fold, 3-fold, and 7 -fold increases in the cosmic ray rate at the top of the atmosphere are compared to the observed increase beginning $44 \mathrm{kyr}$ ago. The large increase in $\Delta^{14} \mathrm{C}(\%)$ is consistent with a 7-fold annual increase in the cosmic ray rate but inconsistent with the maximum possible 2-3 fold increases calculated by Masarik and Beer (Masarik \& Beer 1999) assuming Earth's magnetic field were to vanish. A 2-fold increase in the cosmic ray rate would require $16 \mathrm{kyr}$ for $\Delta^{14} \mathrm{C}(\%)$ to increase by the amount observed 44-40 kyr ago.

(A color version of this figure is available in the online journal.)

\subsection{Comparison of the Near-Earth $S N$}

The relative increases in $\Delta^{14} \mathrm{C}(\%)$ from the four near-Earth $\mathrm{SNe}$ can be compared on a common, renormalized scale. In Figure 5 the decay of ${ }^{14} \mathrm{C}$ from earlier events has been subtracted and total integrated $\Delta^{14} \mathrm{C}(\%)$ renormalized to that of $\mathrm{SN} 44 \mathrm{kyrBP}$. The time scale has been adjusted to $t=0$ at the time of each SN explosion. The pattern of $\Delta^{14} \mathrm{C}(\%)$ production for each of the $\mathrm{SNe}$ is remarkably similar, as if they were standard candles. Each SN can be described by a sudden increase in $\Delta^{14} \mathrm{C}(\%)$ at the time of the explosion, followed by a quiescent period of $\approx 1500 \mathrm{yr}$ during which little additional radiocarbon was produced, and culminating with a rapid production of ${ }^{14} \mathrm{C}$ for $2000 \mathrm{yr}$. Then the excess accumulated ${ }^{14} \mathrm{C}$ decays with a 5730 yr half-life. The most recent SN22kyrBP radiocarbon data have the highest statistical precision, while data from earlier SN have progressively poorer precision as the amount of remaining ${ }^{14} \mathrm{C}$ decreases. The uncertainties in the relative $\mathrm{SN} \Delta \Delta^{14} \mathrm{C}(\%)$ measurements shown in Figure 5 can be estimated by the fluctuations in adjacent data points.

\subsubsection{Distances of the Near-Earth SNe}

The strong similarity in radiocarbon production for the four near-Earth SNe suggests that the distance of each SN from Earth can be estimated assuming that ${ }^{14} \mathrm{C}$ production is inversely proportional to the square of the $\mathrm{SN}$ distance from Earth. If SN22kyrBP is the Vela SN that exploded 250 pc from Earth, and each SN emitted comparable $\gamma$-ray energy, then the distance of the other $\mathrm{SNe}$ can be determined. These assumptions indicate that SN44kyrBP exploded $\approx 110 \mathrm{pc}, \mathrm{SN} 37 \mathrm{kyrBP} \approx 180 \mathrm{pc}$, and $\mathrm{SN} 32 \mathrm{kyrBP} \approx 160 \mathrm{pc}$ from Earth. The absolute increases in $\Delta^{14} \mathrm{C}(\%)$ for each $\mathrm{SN}$ used to estimate the $\mathrm{SN}$ ages are shown

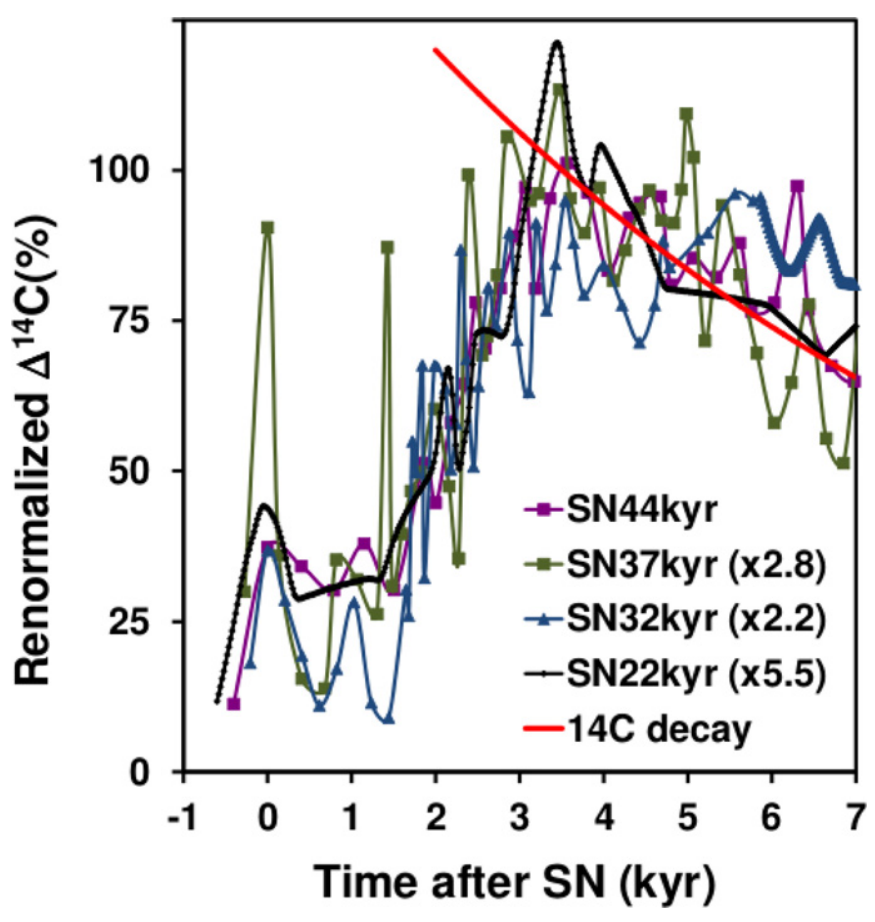

Figure 5. Comparison of radiocarbon production patterns four the four prehistoric SNe. The initial time $t=0$ for each event is the time of the initial SN explosion. The $\Delta^{14} \mathrm{C}(\%)$ data have been renormalized to the $\mathrm{SN} 44 \mathrm{kyrBP}$ data by a factor shown in the legend. The background of ${ }^{14} \mathrm{C}$ decay from earlier $\mathrm{SN}$ has been subtracted. In each case there is a sudden increase in $\Delta^{14} \mathrm{C}(\%)$ from cosmic $\gamma$-rays emitted at the time of the SN explosion, followed by a $1500 \mathrm{yr}$ hiatus, and concluding with a steady increase in radiocarbon for $2000 \mathrm{yr}$ from cosmic $\gamma$-rays induced by the interaction of cosmic rays produced by diffusive shock acceleration in the SNR and interacting with the accumulated SNR mass. This is followed by a decrease in $\Delta^{14} \mathrm{C}(\%)$ with the ${ }^{14} \mathrm{C}$ half-life (red line). The data for SN22kyrBP are most precise with statistical uncertainties falling within the data points. Statistical uncertainties for the earlier SN are consistent with the scattering of values around the $\mathrm{SN} 22 \mathrm{kyrBP}$ data. The pattern of radiocarbon increase for each $\mathrm{SN}$ is nearly identical as if they are standard candles.

(A color version of this figure is available in the online journal.)

Table 2

Data for Four Prehistoric Supernovae Observed in the Radiocarbon, ${ }^{10} \mathrm{Be}$, and $\mathrm{NO}_{3}^{-}$Records

\begin{tabular}{lccccc}
\hline \hline $\begin{array}{l}\text { Date } \\
(\mathrm{kyr} B P)\end{array}$ & $\begin{array}{c}\text { Distance } \\
(\mathrm{pc})\end{array}$ & $\begin{array}{c}\Delta^{14} \mathrm{C}^{\mathrm{b}} \\
(\%)\end{array}$ & $\begin{array}{c}\Delta^{14} \mathrm{C}^{\mathrm{c}} \\
(\%)\end{array}$ & $\begin{array}{c}\mathrm{NO}_{3}^{-\mathrm{d}} \\
(\mathrm{ppb})\end{array}$ & $\begin{array}{c}{ }^{10} \mathrm{~B} /{ }^{9} \mathrm{Be}^{\mathrm{e}} \\
\left(\times 10^{-6}\right)\end{array}$ \\
\hline 44 & $\approx 110$ & 100 & 26 & 21 & 1.2 \\
37 & $\approx 180$ & 36 & 19 & 14 & 3.4 \\
32 & $\approx 160$ & 45 & 7 & 6 & 2.4 \\
22 (Vela SN) & $250 \pm 30$ & 18 & 6 & 9 & 2.2 \\
\hline
\end{tabular}

Notes.

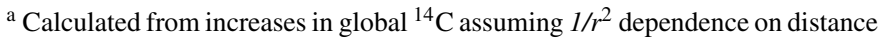
with respect to $\mathrm{SN} 22 \mathrm{kyrBP}$.

b Increase in global radiocarbon corrected for decay from ${ }^{14} \mathrm{C}$ produced by previous SN.

${ }^{c}$ Increase in atmospheric radiocarbon at the time of the SN explosion.

${ }^{d}$ Nitrate increase at the time of the SN observed in Antarctic Taylor Dome ice (Mayewski et al. 1996).

${ }^{\text {e }}$ Increase in ${ }^{10} \mathrm{Be} /{ }^{9} \mathrm{Be}$ observed at the time of the $\mathrm{SN}$ in ocean sediments from the Southeastern margin of New Guinea (Leduc et al. 2006).

in Table 2. The assumption that each $\mathrm{SN}$ emitted comparable amounts of $\gamma$-ray energy may be arbitrary, requiring further investigation, although any significant variation in luminosity could lead to less reasonable $\mathrm{SNe}$ distances. 


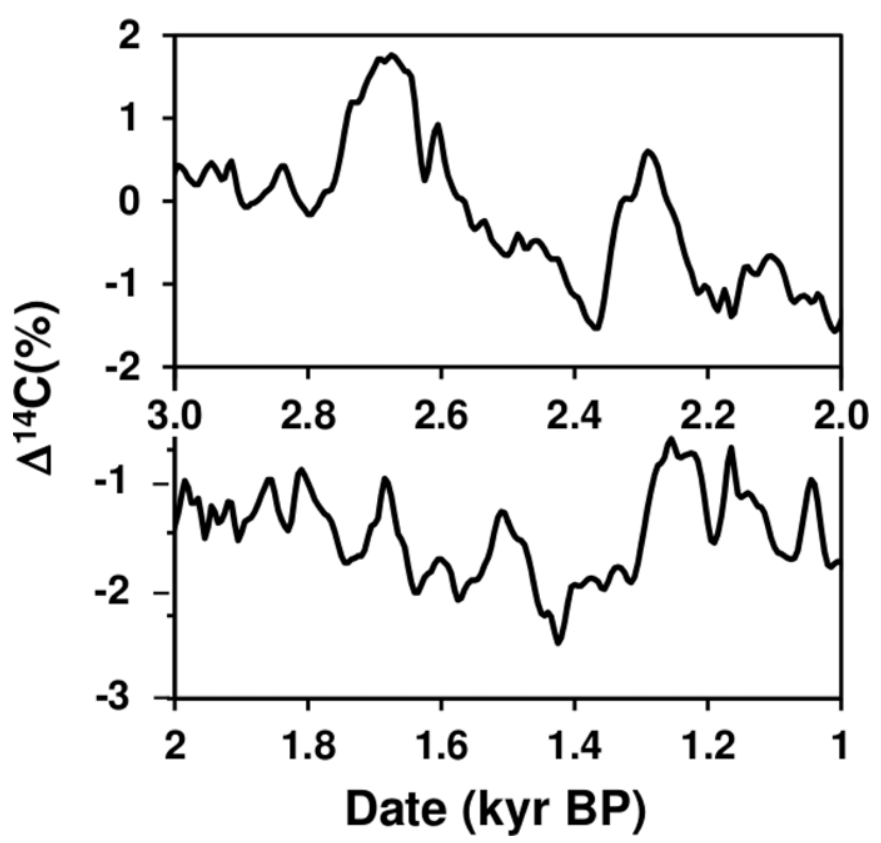

Figure 6. Numerous, additional, small sudden increases in $\Delta^{14} \mathrm{C}$ are observed throughout the radiocarbon record. For example, at least nine increases of $1 \%-2 \%$ are seen in the interval from 1-3 kyr BP. These events may correspond to more distant $\mathrm{SNe}$, explosions in the center of the galaxy, $\gamma$-ray bursts, solar flares, or interruptions to the global carbon cycle.

\subsection{Other Radiocarbon Events}

The radiocarbon record is rife with small, sudden increases in ${ }^{14} \mathrm{C}$ of order $1 \%-2 \%$, as shown for the interval of $1-3 \mathrm{kyr}$ BP in Figure 6. Some of these increases may be associated with more distant $\mathrm{SNe}$, although it is likely that others are due to explosions in the center of the galaxy, $\gamma$-ray bursts, solar flares, or other celestial phenomena. Some may be due to interruptions in the global carbon cycle when excess radiocarbon may accumulate in the atmosphere. One such event was previously reported to occur around 774-775 AD, based on the analysis of radiocarbon in Japanese cedar tree rings (Miyake et al. 2012). This event is also seen in the INTCal04 radiocarbon record. It is not clear whether this event is from the explosion of a near-Earth SN, although it may be related to the "red crucifix" seen in Britain's evening sky in $774 \mathrm{AD}$ (Lovett 2012). Atmospheric radiocarbon increased by about $1.2 \%$, which is $1 / 5$ of the increase observed for SN22kyrBP and would correspond to SN774 exploding $560 \mathrm{pc}$ from Earth.

A much larger 6\% increase in radiocarbon is seen in Figure 7 about 13 kyr ago near the onset of the Younger Dryas, a $1300 \mathrm{yr}$ period of severe global cooling. Unlike the increases ascribed to earlier $\mathrm{SNe}$, this event is characterized by a steady increase in radiocarbon for $\approx 500 \mathrm{yr}$ followed by a steady decrease to previous levels. Although this event appears to have increased atmospheric radiocarbon significantly, the increase is not as sudden as for the other SN and it is not followed by a second, large radiocarbon increase from $\gamma$-rays produced in a SNR. One possible explanation is that this increase is due to interruption of North Atlantic ocean circulation (Broecker 2006). It has also been proposed that the cause of the Younger Dryas was the impact of a large, fragmented comet (Firestone et al. 2007; Napier 2010). Coincidentally, carbon found in the Younger Dryas impact layer often has very young radiocarbon dates (Firestone 2009), up to several hundred years into the future, that are inconsistent with their stratigraphic origin. It is

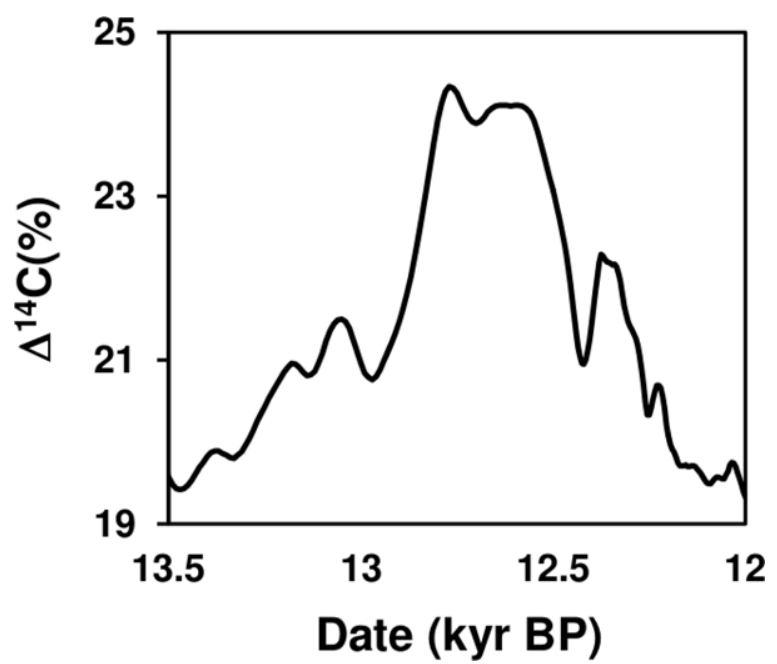

Figure 7. Event at $13 \mathrm{kyr} \mathrm{BP}$ increased atmospheric radiocarbon by $6 \%$, comparable to the near-Earth SNe, but doesn't display the signature of other SNe events. The $13 \mathrm{kyr}$ radiocarbon increase coincides with the time of the Younger Dryas cooling event and may be associated with an interruption of North Atlantic ocean circulation (Broecker 2006) or possibly a comet impact at that time (Firestone et al. 2007; Napier 2010).

tempting to conclude that this excess radiocarbon arrived with a comet, although no mechanism for such an event has yet to be established. Additional possibilities such as a disruption of the solar or Earth magnetic fields need to be explored and the explanation of this event will require additional research.

\section{ADDITIONAL PREHISTORIC SN EVIDENCE}

Although radiocarbon provides a detailed record of the influx of cosmic rays from prehistoric, near-Earth $\mathrm{SNe}$, there should also be additional evidence in the geological records from other cosmogenic isotopes. Cosmic $\gamma$-rays can also affect atmospheric chemistry by breaking $\mathrm{N}_{2}$ and $\mathrm{O}_{2}$ molecular bonds to form $\mathrm{NO}_{x}$ products that are preserved in polar ice cores. These data can provide a general confirmation of the timing of the cosmic ray events but since they are not preserved in a global equilibrium record, as is carbon, they do not provide as strong evidence that they are associated with $\mathrm{SNe}$.

\subsection{Cosmogenic ${ }^{10}$ Be Evidence}

${ }^{10} \mathrm{Be}$ is produced by cosmic ray spallation of the atmosphere and has been observed in Gulf of California marine sediments (McHargue et al. 1995) as seen in Figure 8. Rapid increases in ${ }^{10} \mathrm{Be}$ occurred at $\approx 32$ - and $\approx 44-\mathrm{kyr} \mathrm{BP}$. The magnitude of these increases can be affected by the variable influx of dust that is depleted in ${ }^{10} \mathrm{Be}$. McHargue et al. proposed that the sudden increases in ${ }^{10} \mathrm{Be}$ were due to a sudden change in the cosmic ray flux from nearby $\mathrm{SNe}$ events. Later investigators revised this interpretation assuming that these increases were due to decreases in Earth's magnetic field. As I have shown, only modest radiocarbon increases are correlated with variations in Earth's magnetic field. The observed ${ }^{10} \mathrm{Be}$ abundance fluctuations were as large as 5-fold and appear too significant and rapid to be explained by magnetic field fluctuations.

Similar increases in the ${ }^{10} \mathrm{Be} /{ }^{9} \mathrm{Be}$ ratio found in an ocean core from the Southeastern margin of New Guinea (Leduc et al. 2006) near the times of the 44, 37, 32, and possibly $22 \mathrm{kyr}$ $\mathrm{SNe}$ are shown in Figure 8 . The ${ }^{10} \mathrm{Be} /{ }^{9} \mathrm{Be}$ ratio measurements are a better measure of ${ }^{10} \mathrm{Be}$ enrichment, although they too are 


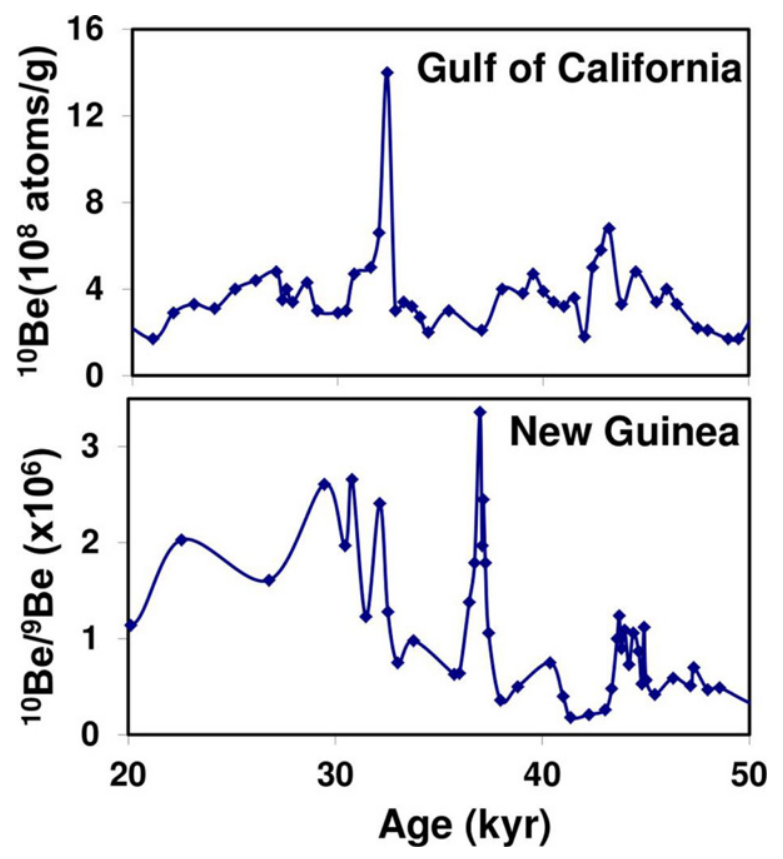

Figure 8. ${ }^{10} \mathrm{Be}$ abundance in marine sediment cores. ${ }^{10} \mathrm{Be}$ is produced by the spallation of oxygen and nitrogen atoms by cosmic rays in the atmosphere and deposited with dust across the Earth. Increases in ${ }^{10} \mathrm{Be}$ abundance in Gulf of California (McHargue et al. 1995) marine sediments are observed 32 and 44 kyr ago and the ${ }^{10} \mathrm{Be} /{ }^{9} \mathrm{Be}$ ratios from an ocean core taken off the Southeastern margin of New Guinea (Leduc et al. 2006) increased 44, 37, 32, and possibly $22 \mathrm{kyr}$ ago, coinciding with the radiocarbon dates for the four prehistoric SNe. (A color version of this figure is available in the online journal.)

subject to dilution from ordinary dust. The magnitudes of these increases in the ${ }^{10} \mathrm{Be} /{ }^{9} \mathrm{Be}$ ratios are included in Table 2 and are proportional to the $\Delta^{14} \mathrm{C}(\%)$ increases 37,32 , and $22 \mathrm{kyr}$ ago, although lower ${ }^{10} \mathrm{Be} /{ }^{9} \mathrm{Be}$ ratios are seen $44 \mathrm{kyr}$ ago, possibly due to sample dilution from the deposition by large quantities of dust depleted in ${ }^{10} \mathrm{Be}$. No increase in the ${ }^{10} \mathrm{Be} /{ }^{9} \mathrm{Be}$ ratio has been observed near the time of the Younger Dryas event.

\subsubsection{Additional SNe in the ${ }^{10}$ Be Record}

Radiocarbon is sensitive to a range of $\approx 50$ kyr because of its relatively short $5730 \mathrm{yr}$ half-life. We expect many similar near-Earth SNe to have occurred before then. These SNe can be observed in earlier ${ }^{10} \mathrm{Be} /{ }^{9} \mathrm{Be}$ sediment records because of the much longer ${ }^{10} \mathrm{Be}$ half-life $\left(1.51 \times 10^{6} \mathrm{yr}\right)$ (Hofmann et al. 1987). In addition to the 4 near-Earth $\mathrm{SNe}$ during the past 50 kyr 19 additional significant peaks are observed in ${ }^{10} \mathrm{Be} /{ }^{9} \mathrm{Be}$ ratio between 50-300 $\mathrm{kyr}$ in the marine sedimentary sequence at the Portuguese margin in the Northeast Atlantic (Carcaillet et al. 2004) as shown in Figure 9. Their ages and distances are estimated from their relative magnitudes and are given in Table 3. Although the assignment of these peaks to $\mathrm{SNe}$ is more tenuous than those seen in the radiocarbon data, their average frequency is $13 \mathrm{kyr}$, which is comparable to the historical SN rate. The near-Earth $\mathrm{SNe}$ rate for the past $50 \mathrm{kyr}$ is consistent with $\approx 20$ SNe exploding $<300 \mathrm{pc}$ from Earth during the $250 \mathrm{kyr}$ interval. This suggests that nearly all, of the peaks in ${ }^{10} \mathrm{Be} /{ }^{9} \mathrm{Be}$ are $\mathrm{SNe}$ signatures and a total of $\approx 23$ prehistoric, near-Earth SNe have exploded during the past $300 \mathrm{kyr}$.

\subsection{Cosmogenic ${ }^{36} \mathrm{Cl}$ and ${ }^{26} \mathrm{Al}$ Evidence}

A significant increase in ${ }^{36} \mathrm{Cl}\left(t_{1 / 2}=3.013 \times 10^{5} \mathrm{yr}\right)$ concentration is observed in the Greenland GRIP ice core (Baumgartner

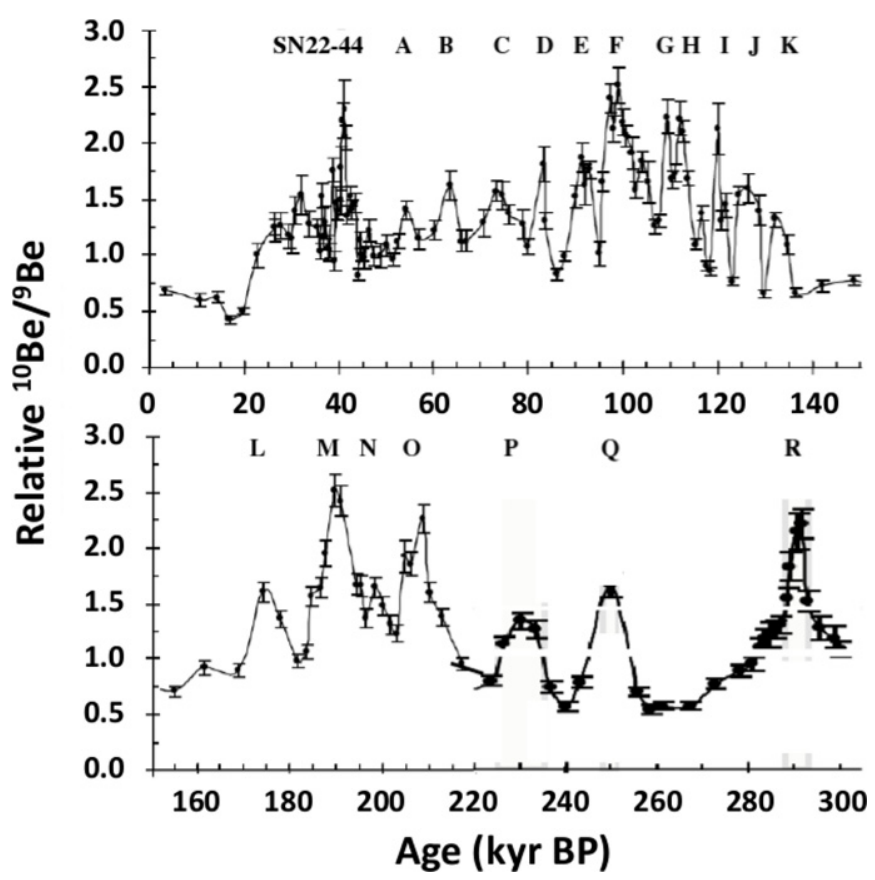

Figure 9. Evidence of earlier near-Earth $\mathrm{SNe}$ in the ${ }^{10} \mathrm{Be}$ marine sediment profile. The $300 \mathrm{kyr}{ }^{10} \mathrm{Be} /{ }^{9} \mathrm{Be}$ ratio record at the Portuguese margin in the Northeast Atlantic (Carcaillet et al. 2004) shows significant peaks corresponding to the four near-Earth $\mathrm{SNe}$ seen in the radiocarbon record. In addition, 19 additional peaks in ${ }^{10} \mathrm{Be} /{ }^{9} \mathrm{Be}$ between $50-300 \mathrm{kyr}$ likely correspond to near Earth SNe. These SNe are labeled $\mathrm{A}-\mathrm{S}$ and their ages and distances are given in Table 3.

Table 3

Ages and Estimated Distances of SN Deduced from ${ }^{10} \mathrm{Be} /{ }^{9} \mathrm{Be}$ Ratios at the Portuguese Margin in the Northeast Atlantic (Carcaillet et al. 2004) Shown in Figure 9

\begin{tabular}{lcccccccc}
\hline \hline SN & $\begin{array}{c}\text { Age } \\
(\mathrm{kyr})\end{array}$ & $\begin{array}{c}\text { Distance } \\
(\mathrm{pc})\end{array}$ & SN & $\begin{array}{c}\text { Age } \\
(\mathrm{kyr})\end{array}$ & $\begin{array}{c}\text { Distance } \\
(\mathrm{pc})\end{array}$ & SN & $\begin{array}{c}\text { Age } \\
(\mathrm{kyr})\end{array}$ & $\begin{array}{c}\text { Distance } \\
(\mathrm{pc})\end{array}$ \\
\hline $\mathrm{A}$ & 57 & 220 & $\mathrm{H}$ & 110 & 132 & $\mathrm{~N}$ & 195 & 114 \\
$\mathrm{~B}$ & 66 & 192 & $\mathrm{I}$ & 115 & 125 & $\mathrm{O}$ & 203 & 205 \\
$\mathrm{C}$ & 79 & 205 & $\mathrm{~J}$ & 123 & 116 & $\mathrm{P}$ & 214 & 125 \\
$\mathrm{D}$ & 86 & 153 & $\mathrm{~K}$ & 129 & 142 & $\mathrm{Q}$ & 238 & 162 \\
$\mathrm{E}$ & 95 & 145 & $\mathrm{~L}$ & 135 & 159 & $\mathrm{R}$ & 270 & 125 \\
$\mathrm{~F}$ & 102 & 108 & $\mathrm{M}$ & 181 & 159 & $\mathrm{~S}$ & 295 & 127 \\
$\mathrm{G}$ & 107 & 173 & & & & & & \\
\hline
\end{tabular}

et al. 1998) 38 and $43 \mathrm{kyr}$ ago. ${ }^{36} \mathrm{Cl}$ is also observed in pack rat middens (Plummer et al. 1997) with significant peaks occurring 22 and $32 \mathrm{kyr}$ ago, and a remarkably large peak near the time of the Younger Dryas as seen in Figure 10. Significant increases in ${ }^{36} \mathrm{Cl}$ concentration are observed in the Greenland GRIP ice core (Baumgartner et al. 1998; Muscheler et al. 2005) $\approx 24, \approx 32$, and $\approx 40-36$ kyr ago. Similar increases in ${ }^{10} \mathrm{Be},{ }^{26} \mathrm{Al}\left(t_{1 / 2}=7.2 \times\right.$ $10^{5} \mathrm{yr}$ ), and ${ }^{36} \mathrm{Cl}$ are reported $\approx 41 \mathrm{kyr}$ ago in the Greenland GISP2 ice core (Nishiizumi et al. 2005).

\subsection{Nitrate Accumulation Evidence}

The nitrate concentration in the atmosphere increases during strong cosmic ray events due to an increase in the rate of ionization of $\mathrm{O}_{2}$ and $\mathrm{N}_{2}$ leading to the generation of free electrons and ions. These electrons are captured by neutral atoms and in a chain of chemical reactions $\mathrm{NO}_{3}^{-}$ions are generated. After hydration the $\mathrm{NO}_{3}^{-}$ions precipitate to Earth's surface. Large increases in nitrate accumulation are observed in the 


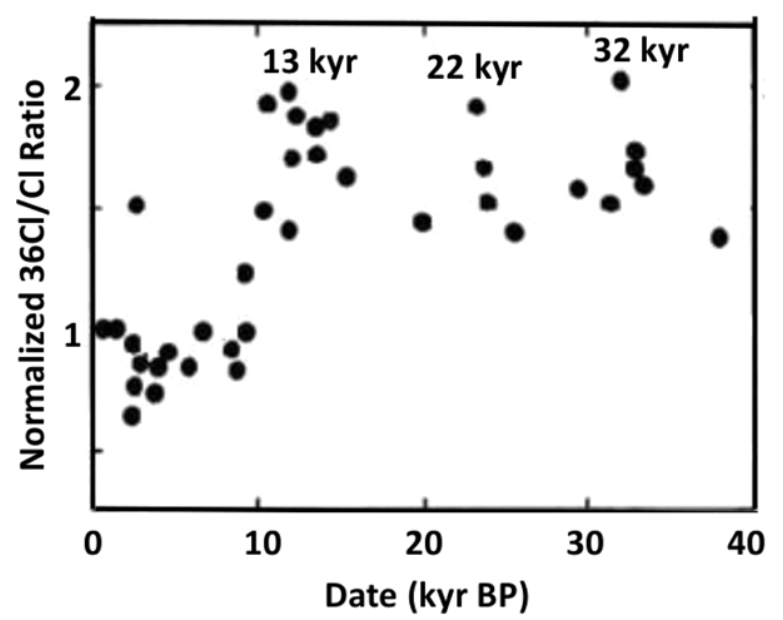

Figure 10. ${ }^{36} \mathrm{Cl} / \mathrm{Cl}$ ratios measured in fossil packrat midden urine (Plummer et al. 1997). Distinct increases are observed 22 and $32 \mathrm{kyr}$ ago corresponding to the times of the SNe observed in the radiocarbon calibration data. An additional large increase in ${ }^{36} \mathrm{Cl} / \mathrm{Cl}$ occurred $\approx 13 \mathrm{kyr}$ ago, at the time of the Younger Dryas which remains unexplained although it is coincident with the global ${ }^{14} \mathrm{C}$ increase at that time.

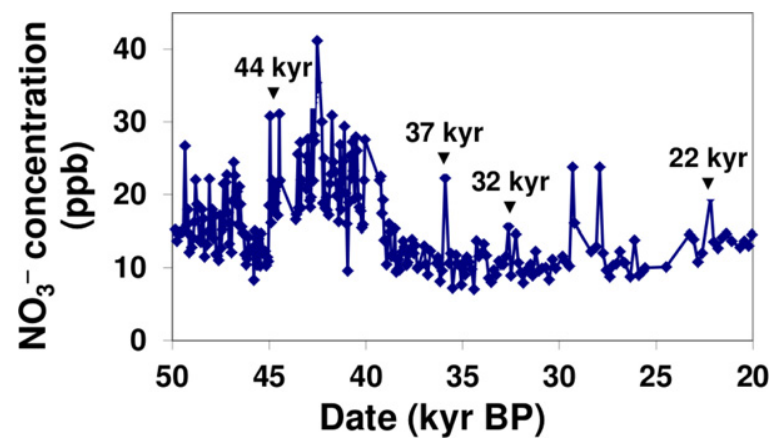

Figure 11. $\mathrm{NO}_{3}^{-}$increases corresponding to the near-Earth $\mathrm{SNe}$ explosions. Nitrate concentrations measured in East Antarctic Taylor Dome ice (Mayewski et al. 1996) increased significantly following each prehistoric SN. Similar increases in nitrate concentrations have been observed following the historical supernovae (Rood et al. 2003; Dreschhoff \& Laird 2006).

(A color version of this figure is available in the online journal.)

East Antarctic ice at Taylor Dome (Mayewski et al. 1996), as shown in Figure 11, coinciding with the times of the four prehistoric $\mathrm{SN}$ explosions and they are followed by a second broad $\mathrm{NO}_{3}^{-}$increase consistent with the arrival of SNR cosmic $\gamma$-rays. The size of the initial increases in nitrate accumulation at the times of the $\mathrm{SN}$ explosions are comparable to the increases in radiocarbon at those times as shown in Table 2.

\section{GLOBAL RADIOCARBON CALORIMETER}

The Earth can be used as a calorimeter to determine the cosmic ray energy released by the nearby SNe. Global radiocarbon is continuously produced by high energy galactic cosmic rays from distant sources. It requires $>10 \mathrm{MeV}$ per primary or secondary particle in order to produce neutrons by nuclear reactions with the atmosphere. Lower energy solar energetic particles ordinarily contribute $\approx 0.25 \%$ of total radiocarbon (Kovaltsov et al. 2012). If the distance $r$ to a near-Earth $\mathrm{SN}$ is known, then the $\gamma$-ray energy released by that $\mathrm{SN}$ can be calculated from the energy required to produce the observed increase in global radiocarbon.

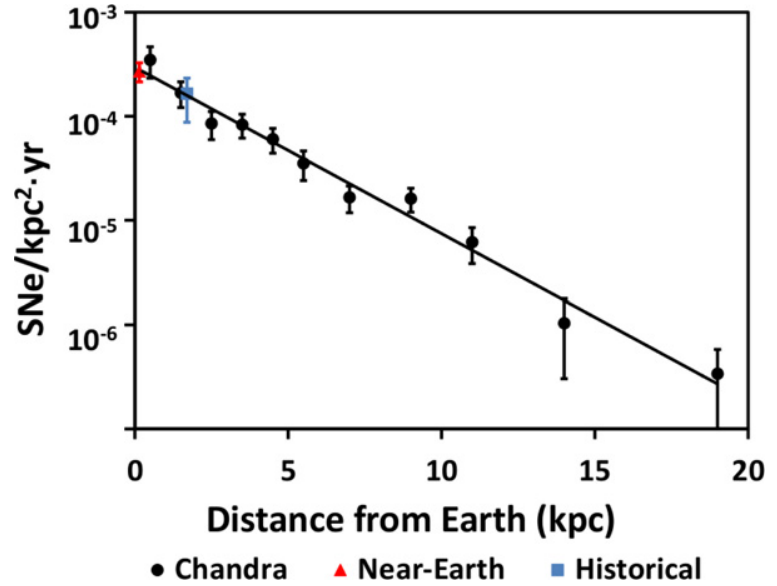

Figure 12. Distribution of SNR from the Chandra Galactic SNR Catalog normalized to the near-Earth SNe rate from this work.

(A color version of this figure is available in the online journal.)

\subsection{Background Radiocarbon Production}

\subsubsection{Distribution of Galactic SNe}

Assuming that the average interval between SNe less than $r=0.3 \mathrm{kpc}$ from Earth is $T(r)=13 \mathrm{kyr}$, then the probability $P(r)$ of a SN exploding in the galactic disk near to Earth is given by

$$
P(r)=\frac{1}{\pi r^{2} T(r)}=2.7(6) \times 10^{-4} \mathrm{kpc}^{-2} \mathrm{yr}^{-1} .
$$

If that rate were constant across the $30 \mathrm{kpc}$ diameter galactic plain this would suggest a galactic SN rate of $190 \mathrm{kyr}^{-1}$, which significantly exceeds the observed rate of $19 \pm 11 \mathrm{kyr}^{-1}$ (Diehl et al. 2006). From Monte Carlo calculations and a galactic model consisting of thin, old, and thick stellar disks, and assuming the historical SNe exploded within the thin disk, it was calculated (Tammann et al. 1994) that the galactic SN rate is $25 \pm 6 \mathrm{kyr}^{-1}$, which is comparable with the observation of Diehl et al. The historical SN rate within $\approx 3 \mathrm{kpc}$ of Earth is $6 \mathrm{kyr}^{-1}$ or $\approx 25 \%$ of the galactic rate, even though this region represents only $4 \%$ of the area of the galactic disk. This demonstrates that Earth is in a very active region of the galaxy. The $\mathrm{SN}$ rate at larger distances from Earth must be substantially lower to account for the total galactic rate.

The dependence of the SNe rate on distance from the Earth can be estimated from the distribution of SNR distances reported in the Chandra Galactic SNR Catalog. Figure 12 shows the binned probability of 118 SNR, 0.25-22 kpc from Earth, normalized to the near-Earth SNe rate. The rate of observed SNR decreases exponentially with distance $r$ from Earth and can be described by the equation

$$
P(r)=0.00030 \times e^{-0.37 r}
$$

This equation agrees well with the observed historical $\mathrm{SN}$ rate $P(r=3.4 \mathrm{kpc})=1.6(7) \times 10^{-4} \mathrm{kpc}^{-2} \mathrm{yr}^{-1}$. Integrating Equation (3) over the range of SNR reported in the Chandra catalog gives a galactic SNe rate of $14 \pm 3 \mathrm{kyr}^{-1}$, which is consistent with the observed rate but slightly lower than the calculated rate. This result confirms that the near-Earth $\mathrm{SNe}$ rate determined from the radiocarbon and ${ }^{10} \mathrm{Be} /{ }^{9} \mathrm{Be}$ data is consistent with the galactic rate, supporting the assignment of these events as $\mathrm{SNe}$ and not other cosmic or terrestrial occurrences. 


\subsubsection{Modern Radiocarbon Production Rate}

The abundance of radiocarbon in 1950 was ${ }^{14} \mathrm{C} / \mathrm{C}=1.245 \times$ $10^{-12}$ (Roberts \& Southon 2007) and the global carbon reservoir is $42.06 \times 10^{12}$ metric tons (Schimel 1995), so the size of the modern global ${ }^{14} \mathrm{C}$ pool in 1950 was 52.4 metric tons $(52,400 \mathrm{~kg})$. From the radiocarbon decay curve for the past $18 \mathrm{kyr}$, it was determined that $\Delta^{14} \mathrm{C}_{1950}=5 \% \pm 2 \%$ in 1950 was from the decay of earlier near-Earth SN explosions. The background global radiocarbon reservoir, defined where $\Delta^{14} \mathrm{C}_{0}=0$, is produced by distant cosmic sources. The decay rate of the background ${ }^{14} \mathrm{C}$ is in equilibrium with its production rate assuming the distant sources remain constant. The background rate of global radiocarbon production $R_{0}$ is given by

$$
\begin{aligned}
R_{0}= & \frac{\lambda N_{1950}\left(1-\Delta^{14} C_{1950}\right)}{A_{E}} \\
& =1.61 \text { atoms cm } \mathrm{cm}^{-2} \mathrm{~s}^{-1}
\end{aligned}
$$

where the ${ }^{14} \mathrm{C}$ decay constant $\lambda=0.000121 \mathrm{yr}^{-1}(3.83 \times$ $\left.10^{-12} \mathrm{~s}^{-1}\right)$, the size of the global radiocarbon pool in 1950 was $N_{1950}=2.25 \times 10^{30}$ atoms, and the area of Earth's surface is $A_{E}=5.1 \times 10^{18} \mathrm{~cm}^{2}$. This value is consistent with the modern radiocarbon deposition rate of 1.64 atoms $\mathrm{cm}^{-2} \mathrm{~s}^{-1}$ calculated (Kovaltsov et al. 2012) using a numerical Monte-Carlo model.

\subsubsection{Radiocarbon Production Rate from Cosmic $\gamma$-Rays}

A significant amount of the background radiocarbon production comes from cosmic $\gamma$-rays emitted following the explosions of distant $\mathrm{SNe}$. The yield of radiocarbon produced by a SN exploding at a distance $r$ from Earth is $Y=c / r^{2}$, where $c$ can be determined from the SN44kyrBP data in Table 2 by

$$
c=\frac{N_{44 \mathrm{kyr}}}{\lambda N_{0}} R_{0} r_{44 \mathrm{kyr}}^{2}=161 \text { atoms } \mathrm{cm}^{-2} \mathrm{~s}^{-1}
$$

assuming SN44kyrBP exploded $r_{44 \mathrm{kyr}}=0.11 \mathrm{kpc}$ from Earth and doubled global radiocarbon so that $N_{44 \mathrm{kyr}}=N_{0}$. The rate of radiocarbon production from distant $\gamma$-ray sources, $R_{0}^{\gamma}>$ $0.3 \mathrm{kpc}$ from Earth, can then be calculated as

$$
\begin{aligned}
R_{0}^{\gamma}= & \int_{0.3}^{22} 2 \pi r P(r) Y d r=\int_{0.3}^{22} \frac{0.303 e^{-0.37 r}}{r} d r \\
& =0.44 \pm 0.09 \text { atoms cm } \mathrm{cm}^{-2} \mathrm{~s}^{-1}
\end{aligned}
$$

indicating that $\approx 27 \%$ of the modern radiocarbon production rate is produced by cosmic $\gamma$-rays from distant $\mathrm{SNe}$.

\subsection{Radiocarbon Production at the Time of the Supernova Explosion}

The initial increase in radiocarbon seen at the time of the near-Earth $\mathrm{SNe}$ explosions occurred in the relatively small, $900 \mathrm{~kg}$, pool of atmospheric radiocarbon before it had time to reach equilibrium with the much larger ocean reservoir (Schimel 1995). Since about $12 \%$ of atmospheric radiocarbon exchanges with the ocean annually, this excess atmospheric ${ }^{14} \mathrm{C}$ is completely mixed into the global carbon cycle within $100 \mathrm{yr}$ and global radiocarbon returns to near baseline levels for each SN as seen in Figure 5. The observed increase in atmospheric radiocarbon at the time of each $\mathrm{SN}$ explosion is given in Table 2. When SN44kyrBP exploded it increased atmospheric radiocarbon by $\approx 26 \%$, producing $N_{14}^{0} \mathrm{C}=230 \mathrm{~kg}$

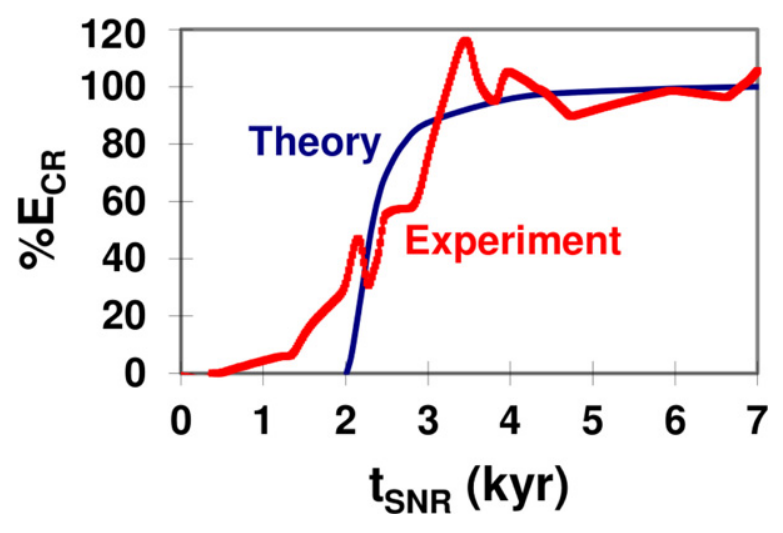

Figure 13. Comparison of the calculated and observed cosmic ray production following a $\mathrm{SNe}$ explosion. The rate of cosmic ray production was calculated for SN1006 (Berezhko et al. 2002) and the observed rate of total radiocarbon production is for $\mathrm{SN} 22 \mathrm{kyrBP}$.

(A color version of this figure is available in the online journal.)

$\left(9.9 \times 10^{27}\right.$ atoms of $\left.{ }^{14} \mathrm{C}\right)$. This increase is comparable to $213 \mathrm{~kg}$ that can be calculated for a SN exploding $0.110 \mathrm{kpc}$ from Earth, primarily from cosmic $\gamma$-rays with energies $<20$ GeV (Povinek \& Tokar 1979). The neutron yield from cosmic SN $\gamma$-rays striking the atmosphere at the time of the explosion has been estimated at $\approx 1000$ neutrons per erg of $\gamma$-ray energy (Lingenfelter \& Ramaty 1970), with about 65\% of these neutrons producing ${ }^{14} \mathrm{C}$ (Damon et al. 1995) so the energy required to produce a ${ }^{14} \mathrm{C}$ atom is $E_{14} \mathrm{C}=0.0015 \mathrm{erg}$. If SN44kyrBP exploded $r_{44 \mathrm{kyr}}=0.11 \mathrm{kpc}=3.4 \times 10^{15} \mathrm{~km}$ from Earth and Earth's radius is $r_{E}=6371 \mathrm{~km}$ then the energy released as $\gamma$-rays at the time of the explosion is given by

$$
E_{\mathrm{SN}}^{0}=4 E_{{ }_{14} \mathrm{C}} N_{{ }^{14} \mathrm{C}}^{0}\left(\frac{r_{44 \mathrm{kyr}}}{r_{E}}\right)^{2}=2 \times 10^{49} \mathrm{erg} .
$$

This energy release is less than $1 \times 10^{50}$ erg reported for SN1006 (Damon et al. 1995), but it is consistent with the predicted $10^{47}-10^{50}$ erg range for hard $\gamma$-ray energy release proposed by various authors (Lingenfelter \& Ramaty 1970; Chupp 1976; Berezinskii et al. 1990).

\subsection{Radiocarbon Production During SNR Cosmic Ray Acceleration}

After each prehistoric SN explosion there was a hiatus of $\approx 1500 \mathrm{yr}$ with no change in $\Delta^{14} \mathrm{C}$ after which the size of the global radiocarbon pool dramatically increased over a period of $\approx 2000$ yr. The rate of cosmic $\gamma$-ray production inferred from the increase in radiocarbon following SN22kyrBP is compared with the calculated cosmic ray production rate (Berezhko et al. 2002) for SN1006 in Figure 13. The agreement is excellent and suggests that the production of cosmic $\gamma$-rays coincides with the acceleration of hadronic cosmic rays that then interact with the mass contained within the SNR.

SN44kryBP doubled the global radiocarbon pool producing $52,400 \mathrm{~kg}$ of radiocarbon $\left(2.25 \times 10^{30}\right.$ atoms of $\left.{ }^{14} \mathrm{C}\right)$. If it required $0.0015 \mathrm{erg}$ to produce an atom of ${ }^{14} \mathrm{C}$, as was assumed at the time of the SN explosion, then SN44kyrBP would have emitted a $3.6 \times 10^{51} \mathrm{erg}$ of $\gamma$-ray energy. That value is clearly too large as it would require all of the energy emitted by the $\mathrm{SN}$ explosion to be converted into $\gamma$-ray energy. However, the $\gamma$-rays produced in the SNR remnant by the more energetic hadronic 


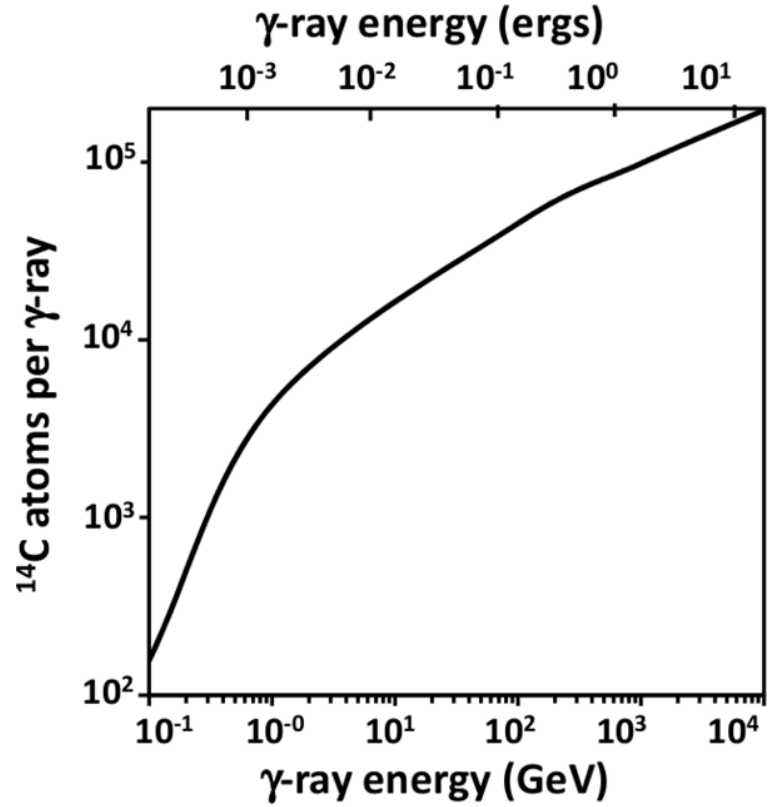

Figure 14. Radiocarbon yield as a function of cosmic ray energy. Data are taken from Kovaltsov et al. (2012), calculated for cosmic ray protons, and extrapolated to $20 \mathrm{TeV}$. It has been assumed here that the yield of ${ }^{14} \mathrm{C}$ from cosmic $\gamma$-rays is similar to that from protons.

cosmic rays will have substantially higher energies and are more efficient in producing radiocarbon when striking Earth's atmosphere. It has been calculated (Kovaltsov et al. 2012) that the ${ }^{14} \mathrm{C}$ yield varies from 4300 atoms $\mathrm{erg}^{-1}$ for a $1 \mathrm{GeV}$ $\gamma$-ray to 200,000 atoms $\mathrm{erg}^{-1}$ for a $10 \mathrm{TeV} \gamma$-ray, as shown in Figure 14. SNRs are most luminous for $<10^{4} \mathrm{yr}$, emitting $\gamma$-rays in the $\mathrm{GeV}$ to $\mathrm{TeV}$ range, where a ratio of $0.3-3 \mathrm{GeV}$ to $0.3-3 \mathrm{TeV} \gamma$-ray flux of $\approx 5$ is representative of young SNR $\gamma$-ray emission (Dermer \& Powale 2013) so a reasonable average neutron yield would be $\approx 20,000 \mathrm{erg}^{-1}$. If $E_{{ }^{14} \mathrm{C}}=$ $0.00005 \mathrm{erg}$, the total $\gamma$-ray energy emitted by the SN44kyrBP $\mathrm{SNR}$ is $\approx 1 \times 10^{50} \mathrm{erg}$, which would be $\approx 1 / 3$ of the total energy expected to be released as cosmic rays (Berezhko et al. 2002), although less than $\approx 4 \times 10^{50}$ erg reported by Castagnoli et al. for Tyrrhenian Sea thermoluminescence data (Castagnoli et al. 1982). This is comparable to the fraction of cosmic $\gamma$-ray energy that was determined to produce background levels of global radiocarbon from distant sources.

The near-Earth SNe all followed a similar pattern of radiocarbon production as shown in Figure 5. In each case no excess radiocarbon production was observed after $3500 \mathrm{yr}$. Type II SNR luminescence has been reported as $\approx 3 \times 10^{36} \mathrm{erg} \mathrm{s}^{-1}$ (Dermer $\&$ Powale 2013), which if sustained for $2000 \mathrm{yr}$ would emit a total of $\approx 2 \times 10^{47} \mathrm{erg}$ of $\gamma$-ray energy. Even if the average $\gamma$-ray energy emitted were $100 \mathrm{TeV}$, it does not appear possible for the near-Earth SNe to have emitted less than $\approx 10^{49} \mathrm{erg}$ of $\gamma$-ray energy. This discrepancy with previous observations cannot be readily explained here and suggests that a more detailed analysis, beyond the scope of this paper, is necessary.

\section{ENVIRONMENTAL CONSIDERATIONS}

It has been shown (Ellis \& Schramm 1995) that direct heat, increased radiation from $\gamma$-rays and cosmic rays, and damage to ozone layer should pose little danger from $\mathrm{SNe}>10 \mathrm{pc}$ from Earth. The local $\mathrm{SN}$ rate suggests that $\mathrm{SNe}<10 \mathrm{pc}$ from Earth occur about once in every 12 million years. When SN44kyrBP

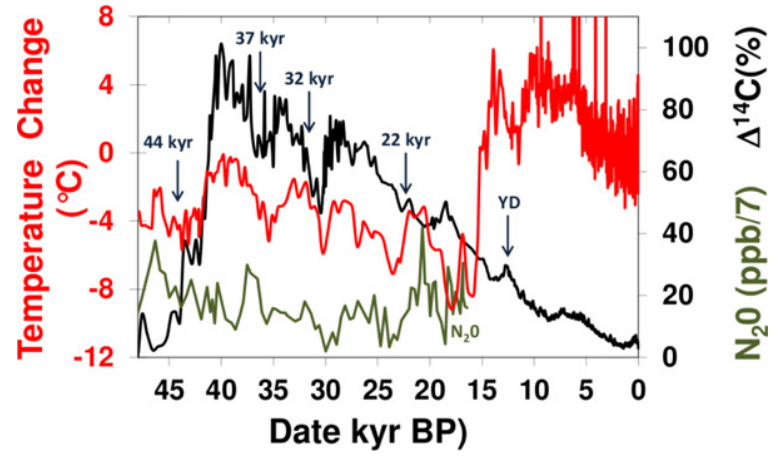

Figure 15. Comparison of the radiocarbon $\Delta^{14} \mathrm{C}$ and Taylor Dome Antarctica (Steig et al. 2000) temperature data. A strong correlation appears to exist between the explosions of near-Earth $\mathrm{SNe}$ and temperature rises of $\approx 3^{\circ} \mathrm{C}-4^{\circ} \mathrm{C}$. The SN44kyr explosion appears $\approx 2$ kyr earlier in the temperature data, based on $\Delta^{18} \mathrm{O}$ measurements, possibly due to age calibration difficulties. These results contradict predictions that increased cosmic ray intensities should decrease global temperatures (Stensmark et al. 1997). $\mathrm{N}_{2} \mathrm{O}$ concentrations are also seen to increase near the times of the SNe in EPICA Dome Antarctica ice core data (Schilt et al. 2010) (lower curve) and may account for the observed temperature increases.

(A color version of this figure is available in the online journal.)

exploded life on Earth would have received $\approx 40$ times the modern cosmic radiation dose near the time of the explosion and $\approx 4$ times the normal dose annually for 1500-3500 yr following the explosion. It has been confirmed by evidence from Antarctic lake sediments (Hodgson et al. 2005) that during the late Pleistocene radiation was $\approx 3$ times higher than during the Holocene. Radiation exposure from near-Earth SNe, while not catastrophic, may have led to punctuated increases in global mutation rates and somatic changes following each event. Cancer deaths would have increased by $\approx 3 \%$ at the time of the explosion but only negligibly later (Pierce et al. 1996).

Cosmic rays are also proposed to cause ionization in the atmosphere seeding cloud formation (Stensmark et al. 1997). This implies that if the cosmic ray rate were to increase, the additional cloud formation would increase Earth's albedo radiating more of the Sun's energy into space and leading to global cooling. This hypothesis can be tested with the nearEarth SN data presented in this paper. In Figure 15 I have compared the radiocarbon calibration data for the past $48 \mathrm{kyr}$ with the Pleistocene global temperature variations derived from $\Delta^{18} \mathrm{O}$ measurements in the Taylor Dome, Antarctica ice core (Steig et al. 2000). Broad temperature increases of $\approx 3^{\circ} \mathrm{C}-4^{\circ} \mathrm{C}$ are observed following each $\mathrm{SN}$ explosion, continuing through the SNR cosmic ray production phase, and then returning to earlier temperature levels. This correlation appears to contradict the predictions of Stensmark et al. It is likely that a sustained increased in the cosmic ray rate would produce significant amounts of $\mathrm{NO}_{x}$ in the stratosphere causing depletion of the ozone layer (Ellis \& Schramm 1995). Loss of the ozone layer increases the exposure of the lower atmosphere to ultraviolet radiation which may contribute to global warming (Hartmann et al. 2000). Nitrous oxide $\left(\mathrm{N}_{2} \mathrm{O}\right)$, a greenhouse gas with 300 times the global warming potential of $\mathrm{CO}_{2}$ (Myhre et al. 2013), is also shown in Figure 15 to increase significantly in the EPICA Dome Antarctica ice core (Schilt et al. 2010) at the times of the near-Earth $\mathrm{SNe} . \mathrm{N}_{2} \mathrm{O}$ may be produced directly by both cosmic radiation (Harteck 1955) and coronal discharges associated with cosmic ray induced lightning (Hill et al. 1984). While this may be the cause of the observed temperature 
increases, global warming is a complex process and further analysis is required to understand these results.

\section{CONCLUSIONS}

The radiocarbon record for the past $50 \mathrm{kyr}$ is completely explained by the occurrence of four, powerful, near-Earth $(<300 \mathrm{pc})$ cosmic ray producing events beginning 44, 37, 32, and $22 \mathrm{kyr}$ ago that produced up to $100 \%$ increases in size of the global radiocarbon pool. These events showed remarkably identical patterns of radiocarbon production, beginning with a sharp increase in atmospheric radiocarbon, followed by a quiescent period of $1500 \mathrm{yr}$ when little excess radiocarbon was produced, and concluding with a $2000 \mathrm{yr}$ interval of rapid increase in global radiocarbon. Each event was then followed by the decay of excess accumulated radiocarbon with the expected ${ }^{14} \mathrm{C}$ half-life $\left(t_{1 / 2}=5730 \mathrm{yr}\right)$.

Previously this excess radiocarbon was attributed to variations in Earth's magnetic field, however I have shown that the increases were too rapid and large to be accounted for in this way, even if Earth's magnetic field disappeared for several millennia. Decay of $\Delta^{14} \mathrm{C}$ for the last $18 \mathrm{kyr}$ with the ${ }^{14} \mathrm{C}$ halflife proves that the entire global radiocarbon pool, not simply the atmospheric component, had increased. Small oscillations of order $2 \%$ in the radiocarbon decay curve for the past $12 \mathrm{kyr}$ were shown to correspond directly to known changes in Earth's magnetic field, demonstrating that some other cosmic ray source must be responsible for the large radiocarbon increases.

Solar flares, $\gamma$-ray bursts, explosions at the center of the galaxy, and other sudden cosmic events have all been ruled out in this analysis because the near-Earth events produced radiocarbon over an extended, $3500 \mathrm{yr}$ time period. This leaves near-Earth $\mathrm{SNe}$ as the only plausible causes of the observed increases in global radiocarbon during the past $50 \mathrm{kyr}$. Analysis of the radiocarbon record provides the following corroborating evidence that these events are SNe.

1. The near-Earth SNe rate is consistent with both the historical and the galactic $\mathrm{SNe}$ rate.

2. The pattern of cosmic $\gamma$-ray production after each $\mathrm{SN}$ follows the theoretical predictions.

3. The timing of the SNe observed in the radiocarbon record is confirmed in terrestrial cosmogenic isotope records.

4. SN22kyrBP can be identified with the Vela SN explosion that exploded $250 \pm 30 \mathrm{pc}$ from Earth.

5. It was determined that $\approx 2 \times 10^{49} \mathrm{erg}$ of $\gamma$-ray energy were released by the $\mathrm{SNe}$ at the time of the explosions which is consistent with expectations.

6. It was determined that $\approx 10^{50}$ erg of $\gamma$-ray energy was later produced in the SNR which is consistent with calculations of cosmic ray production.

7. Approximated $1 / 3$ of the energy emitted as hadronic cosmic rays in the SNR was shown to be converted into $\gamma$-rays and a comparable fraction of the background radiocarbon production was attributed to cosmic $\gamma$-rays.

This analysis is the first observation of the complete cycle of cosmic $\gamma$-ray emission by a SN and its subsequent SNR. The long duration of these events makes the direct observation by traditional astronomical methods impossible. Several surprising results of these observations will require a more detailed analysis in the future.

1. The "standard candle" pattern of cosmic $\gamma$-ray emission for the four near-Earth $\mathrm{SNe}$ observed in the radiocarbon
Table 4

Near-Earth Supernova Explosion Candidates

\begin{tabular}{lccc}
\hline \hline Star & Location & $\begin{array}{c}\text { Dist. } \\
(\mathrm{pc})\end{array}$ & $\begin{array}{c}\text { Mass } \\
\odot\end{array}$ \\
\hline IK Pegasi & Pegasus & 46 & $1.65 / 1.15^{\mathrm{a}}$ \\
Spica & Virgo & 80 & $10.25 / 7.0^{\mathrm{a}}$ \\
Alpha Lupi & Lupus & 141 & 10.1 \\
Antares & Scorpius & 169 & $12.4 / 10^{\mathrm{a}}$ \\
Betelgeuse & Orion & 197 & $7.7-20$ \\
Rigel & Orion & 264 & $18^{\mathrm{b}}$ \\
\hline
\end{tabular}

Notes.

${ }^{a}$ Binary star system.

b Multiple star system.

record is unexpected since it seems surprising that each event would be identical.

2. The assumption that the distance of each SN from Earth scales by $1 / r^{2}$ with respect to global radiocarbon production is arbitrary and cannot be proven at this time.

3. Possible assignment of SN32kyr BP as the Vela SN cannot be ruled from the uncertainties in the SNR size and pulsar distance ages.

4. The observed cosmic $\gamma$-ray energy released by the nearEarth $\mathrm{SNe}$ is larger than that seen today in SNR, although most modern measurements are in historical $\mathrm{SNe}$, which are in a more quiescent stage of cosmic ray production, or in $\mathrm{SNe}$ older than $10^{4} \mathrm{yr}$, whose cosmic ray production has declined.

5. Events observed only in the ${ }^{10} \mathrm{Be} /{ }^{9} \mathrm{Be}$ data provide only limited information on cosmic $\gamma$-ray production due to the poor resolution of these data. Assignment of all of these events as $\mathrm{SNe}$ should be considered tentative at this time.

The radiocarbon record contains considerable information on more distant $\mathrm{SNe}$, as well as solar flares, $\gamma$-ray bursts, explosions at the center of the galaxy, and other cosmic events that may be studied in future work. These studies would certainly benefit from higher precision studies of ${ }^{14} \mathrm{C}$ abundance, possibly at various geographical sites that could provide additional information on the location the near-Earth SNe in the galaxy.

\section{FUTURE SUPERNOVA EXPLOSIONS}

SN1006 exploded with an estimated magnitude of -7.5 , which was about 4 times as bright as Venus. SN44kyrBP exploded 14 times closer than SN1006 and would have had a brightness comparable to the moon, remaining in the sky for many months as the radioactive products of nucleosynthesis decayed. Future near-Earth SNe explosions will certainly provide an astounding light show far exceeding the historical observations.

The explosion of a near-Earth $\mathrm{SN}$ in the future would not be surprising and appears to be overdue. At least six stars $<300 \mathrm{pc}$ from Earth may be considered as SN candidates and are listed in Table 4. IK Pegasi is a binary star system $46 \mathrm{pc}$ from Earth that may evolve into a Type 1a SN. The others should all evolve into Type II SN. None of these potential near-Earth SNe are likely to cause immediate danger to life on Earth, although there appears to be a strong correlation between increased cosmic radiation and global warming that could prove important in modern times should another near-Earth $\mathrm{SNe}$ occur.

This work was supported, in part, by the U.S. Department of Energy Contract DE-AC02-05CH11231. The author is 
especially grateful for helpful discussions and suggestions by Allen West (Geoscience Consulting, Dewey, AZ), Jon Hagstrum (USGS, Menlo Park, CA), Spencer Klein (LBNL, Berkeley, CA), Christopher McKee (University of California, Berkeley, Department of Physics), and Mary Firestone (University of California, Berkeley, Department of Environmental Science Policy and Management.

\section{REFERENCES}

Ackermann, M., Ajello, M., Allafort, A., et al. 2013, Sci, 339, 807

Aschenbach, B., Egger, R., \& Trumper, J. 1995, Natur, 373, 587

Baumgartner, S., Beer, J., Masirik, J., et al. 1998, Sci, 279, 1330

Beck, J. W., Richards, D. A., Edwards, R. L., et al. 2001, Sci, 292, 2453

Benítez, N., Máíz-Apellniz, J., \& Canelles, M. 2002, PhRvL, 88, 081101

Berezhko, E. G., Ksenofontov, L. T., \& Volk, H. J. 2002, A\&A, 395, 943

Berezinskii, V. S., Bulanov, S. V., \& Dogiel, V. A. 1990, Astrophys. of Cosmic

Rays (Amsterdam: North-Holland)

Broecker, W. S. 2006, Sci, 312, 1146

Carcaillet, J., Bourles, D. L., Thouveny, N., \& Arnold, M. 2004, E\&PSL, 219,397

Castagnoli, G. C., Boniino, G., \& Miono, S. 1982, NCimC, 5, 488

Cha, A. N., Sembach, K. R., \& Danks, A. C. 1999, ApJL, 515, L25

Chanmugam, G., Rajasekhar, A., \& Young, E. J. 1995, MNRAS, 276, L21

Chupp, E. L. 1976, Gamma-Ray Astronomy (Bingham, MA: Reidel)

Colgate, S. A., \& White, R. H. 1968, CaJPh, 46, S476

Damon, P. E., Kaimei, D., Kocharov, G. E., Mikheeva, I. B., \& Peristykh, A. N 1995, Radiocarbon, 37, 599

Dermer, C. D., \& Powale, G. 2013, A\&A, 553, A34

de Zeeuw, P. T., Hoogerwerf, R., de Bruijne, J. H. J., Brown, A. G. A., \& Blaauw, A. 1999, ApJ, 117, 354

Diehl, R., Halloin, H., Kretschmer, K., et al. 2006, Natur, 439, 45

Dreschhoff, G., \& Laird, C. 2006, AdSpR, 38, 1307

Ellis, J., \& Schramm, D. N. 1995, PNAS, 92, 235

Ellison, D. C., Decourchelle, A., \& Ballet, J. 2004, A\&A, 413, 189

Elsasser, W., Ney, E. P., \& Wincler, J. R. 1956, Natur, 178, 1226

Fermi, E. 1949, PhRv, 75, 1169

Firestone, R. B. 2009, JCos, 2, 256

Firestone, R. B., West, A., Kennett, J. P., et al. 2007, PNAS, 104, 16016

Godwin, H. 1962, Natur, 195, 984

Green, D. A. 2004, BASI, 32, 335

Harteck, P., \& Dondes, S. 1955, JChPh, 24, 619

Hartmann, D. L., Wallace, J. M., Limpasuvan, V., Thompson, D. W. J., \& Holtan, J. R. 2000, PNAS, 97, 1412

Hernandez, J., Calvet, N., Hartmann, L., et al. 2005, AJ, 129, 856

Hill, R. D., Rinker, R. G., \& Coucouvinos, A. 1984, JGR, 89, 1411
Hillas, A. M. 2005, JPhG, 31, R95

Hodgson, D., et al. 2005, E\&PSL, 236, 765

Hofmann, H. J., Beer, J., Bonani, G., et al. 1987, NIMPB, 29, 32

Hughen, K., Lehman, S., Southen, J., et al. 2004, Sci, 303, 202

Jiang, S. Y., \& Zhao, F. Y. 2007, ChJAA, 7, 325

Kovaltsov, G. A., Mishev, A., \& Usoskin, I. G. 2012, E\&PSL, 337, 114

Leduc, G., Thouveny, N., Bourles, D., Blanchet, C., \& Carcaillet, J. 2006, E\&PSL, 245, 19

Libby, W. F., Anderson, E. C., \& Arnold, J. R. 1949, Science, 109, 227

Lingenfelter, R. E., \& Ramaty, R. 1970, Radiocarbon Variations and Absolute Chronology (New York: Wiley), 513

Lovett, R. A. 2012, Nature News

Masarik, J., \& Beer, J. 1999, JGR, 104, 12099

Mayewski, P. A., Twickler, M. S., Whitlow, S. I., et al. 1996, Sci, 272, 1636

McElhinny, M. W., \& Senanayake, W. E. 1982, JGG, 34, 39

Mchargue, L. R., Damon, P. E., \& Donahue, D. J. 1995, GeoRL, 22, 659

Miyake, F., Nagaya, K., Masuda, K., \& Nakamura, T. 2012, Natur, 486, 240

Muscheler, R., Beer, J., Kubik, P. W., \& Synal, H.-A. 2005, QSRv, 24, 1849

Myhre, G., Shindell, D., Bron, F.-M., et al. 2013, Anthropogenic and Natural Radiative Forcing, Climate Change 2013: The Physical Science Basis. Contribution of Working Group I to the Fifth Assessment Report of the Intergovernmental Panel on Climate Change (New York, NY: Cambridge Univ. Press)

Napier, W. M. 2010, MNRAS, 405, 1901

Nishiizumi, K., Finkel, R. C., \& Welton, K. C. 2005, in Proc. 10th International Conference on Accelerator Mass Spectrometry (Berkeley, CA: GI SP2 Iee Core)

Pierce, D. A., Shimizu, Y., Preston, D. L., Vaeth, M., \& Mabuchi, K. 1996, J. Radiat. Res., 146, 1

Plummer, M. A., Phillips, F. M., Fabryka-Martin, J., et al. 1997, Sci, 277, 538

Povinek, P., \& Tokar, S. 1979, in Proc. 16th International Cosmic Ray Conference, ed. S. Miyake (Tokyo, Japan: Univ. of Tokyo Press), 237

Preibisch, T., Brown, A. G. A., Bridges, T., Guenther, E., \& Zinnecker, H. 2002, ApJ, 124, 404

Reimer, P. J., Baillie, M. G. L., Bard, E., et al. 2003, Radiocarbon, 46, 1029

Reimer, P. J., Baillie, M. G. L., Bard, E., et al. 2009, Radiocarbon, 51, 1111

Reimer, P. J., Hughen, K. A., Guilderson, T. P., et al. 2002, Radiocarbon, 44, 653

Roberts, M. L., \& Southon, J. R. 2007, Radiocarbon, 49, 441

Rood, R. T., Sarazin, C. L., Zeller, E. J., \& Parker, B. C. 2003, Natur, 282, 701

Schilt, A., Baumgartner, M., Blunier, T., et al. 2010, QSRv, 29, 182

Schimel, D. S. 1995, Global Change Biol., 1, 77

Steig, E. J., Morse, D. L., Waddington, E. D., et al. 2000, Geografiska Annaler, $82 \mathrm{~A}, 213$

Stensmark, H., \& Friis-Christensen, E. 1997, JASTP, 59, 1225

Strom, R., Johnston, H. M., Verbunt, F., \& Aschenbach, B. 1995, Natur, 373,590

Tammann, G. A., Loffler, W., \& Schroder, A. 1994, ApJS, 92, 487 